\title{
Oxidative Dehydrogenation of 1-Butene to 1,3-Butadiene Over Metal Ferrite Catalysts
}

\author{
Cory Black $^{1} \cdot$ Grace Currie $^{1} \cdot$ Keith Whiston $^{2} \cdot$ Stephen Sproules $^{1} \cdot$ S. David Jackson ${ }^{1}[$
}

Accepted: 10 March 2021 / Published online: 29 March 2021

(c) The Author(s) 2021

\begin{abstract}
The oxidative dehydrogenation (ODH) of 1-butene to 1,3-butadiene was studied over a series of $\mathrm{AFe}_{2} \mathrm{O}_{4}$ catalysts, where $\mathrm{A}=\mathrm{Zn}, \mathrm{Mn}, \mathrm{Ni}, \mathrm{Cu}, \mathrm{Mg}$ and $\mathrm{Fe}$. The catalysts were characterised by XPS, EPR spectroscopy, BET surface area analysis, Raman spectroscopy and XRD. All the ferrites were active for ODH and gave an order of activity after $80 \mathrm{~h}$ on-stream of $\mathrm{ZnFe}_{2} \mathrm{O}_{4}>\mathrm{NiFe}_{2} \mathrm{O}_{4}>\mathrm{MnFe}_{2} \mathrm{O}_{4}>\mathrm{MgFe}_{2} \mathrm{O}_{4}>\mathrm{CuFe}_{2} \mathrm{O}_{4}>\mathrm{FeFe}_{2} \mathrm{O}_{4}$. All catalysts lost significant surface area (up to $~ 80 \%$ ) under reaction conditions of $0.75: 1: 15$ oxygen:1-butene:steam with an overall GHSV of $10,050 \mathrm{~h}^{-1}$ at $693 \mathrm{~K}^{-\mathrm{Fe}_{3} \mathrm{O}_{4} \text { was }}$ unstable under reaction conditions and was converted to $\mathrm{Fe}_{2} \mathrm{O}_{3}$, which showed very low activity. Nickel ferrite was the only material that gave carbon dioxide as a significant product, all others were selective to 1,3-butadiene. Zinc ferrite gave a steady-state yield of 1,3-butadiene of $\sim 80 \%$. Inversion parameters were determined for the ferrites from XPS and a correlation was obtained between 1,3-butadiene yield and inversion parameter, indicating that $\mathrm{Fe}^{3+}$ in an octahedral hole is a key species in the mechanism of oxidative dehydrogenation. Butene isomerisation and ODH were shown to occur on different sites.
\end{abstract}

Keywords Zinc ferrite $\cdot$ Butadiene $\cdot$ Oxidative dehydrogenation $\cdot 1$-butene $\cdot$ Ferrites

\section{Introduction}

1,3-Butadiene is a global commodity chemical, with around 12 million MT produced annually. It is principally produced as a by-product of steam cracking of naphtha to make ethene, however the move to shale gas steam cracking, especially in the USA, has limited production. Nevertheless, demand for butadiene as a monomer is buoyant, therefore these factors combined have led to an increasing demand for alternative methods of producing 1,3-butadiene. One methodology that is not equilibrium limited is oxidative dehydrogenation (ODH) of butene to produce 1,3-butadiene. Metal ferrites and bismuth molybdates are the two most commonly used groups of catalysts for 1-butene ODH and both have been shown to produce high 1,3-butadiene yields [1-5]. As well

Keith Whiston

Keith.Whiston-1@invista.com

$\triangle$ S. David Jackson

david.jackson@glasgow.ac.uk

1 Centre for Catalysis Research, School of Chemistry, University of Glasgow, Glasgow G12 8QQ, UK

2 INVISTA Textiles (UK) Ltd, The Wilton Centre, Redcar TS10 4RF, UK as producing 1,3-butadiene by an ODH reaction, ferrite catalysts have been shown to catalyse a number of other side reactions, including: combustion, isomerisation and cracking, however much of the literature discussing butene ODH neglects to mention the minor products of the reaction. Kung et al. [6], conducted an absorption/desorption study looking at the relative selectivities' of the reaction products from cis2-butene ODH over zinc ferrite. They found that their product flow consisted of unreacted cis-2-butene, trans-2-butene, 1-butene, 1,3-butadiene and carbon dioxide. They concluded that the oxidative dehydrogenation process occurred on a separate site from the combustion process and that 1,3-butadiene was more readily combusted on the catalyst than the butene isomers. As well as zinc ferrite there have been several studies investigating the use of other metal ferrites as 1-butene ODH catalysts. Lee et al. [7] synthesised a variety of ferrite catalysts with the general formula $\mathrm{M}^{2+} \mathrm{Fe}_{2} \mathrm{O}_{4}$, using the divalent cations $\mathrm{Zn}^{2+}, \mathrm{Mg}^{2+}, \mathrm{Mn}^{2+}, \mathrm{Ni}^{2+}, \mathrm{Co}^{2+}$ and $\mathrm{Cu}^{2+}$. The catalysts were characterised by XRD, BET, XPS and ICP-AES and it was determined that all the metal ferrites produced exhibited a random spinel structure, with divalent and trivalent ions distributed randomly between tetrahedral and octahedral sites. Catalytic activity for the metal ferrites was as follows $\mathrm{ZnFe}_{2} \mathrm{O}_{4}>\mathrm{MgFe}_{2} \mathrm{O}_{4}>\mathrm{MnF}$ 
$\mathrm{e}_{2} \mathrm{O}_{4}>\mathrm{NiFe}_{2} \mathrm{O}_{4}>\mathrm{CoFe}_{2} \mathrm{O}_{4}>\mathrm{CuFe}_{2} \mathrm{O}_{4}$. A relationship was identified between catalytic performance and surface acidity, with zinc ferrite proving to have both the highest yield of butadiene and the highest surface acidity. Surface acidity was investigated because the rate determining step for the dehydrogenation was believed to be the abstraction of an $\alpha$-hydrogen and the acidity of the catalyst was deemed to be an important factor in this process. Over metal ferrites the suggested mechanism for the oxidative dehydrogenation of 1-butene to 1,3-butadiene is a Mars Van Krevelen type mechanism, which proceeds via a $\pi$-allyl-oxy intermediate [8-10]. In the proposed mechanism the catalyst active site is a redox $\mathrm{Fe}^{3+}-\mathrm{O}^{2-}$ site, where initially some of the $\mathrm{O}^{2-}$ ions are hydroxylated by steam in the reactant feed, the 1-butene is then chemisorbed to the surface, before two successive $\alpha$-hydrogen abstractions occur, resulting in the loss of water each time. Following the second $\alpha$-hydrogen abstraction, 1,3-butadiene is formed and desorbs from the catalyst, the $\mathrm{O}^{2-}$ vacancy left on the catalyst surface is replenished with oxygen in the reactant feed and the re-oxidation of the $\mathrm{Fe}^{2+}$ to $\mathrm{Fe}^{3+}$. The initial $\alpha$-hydrogen abstraction is believed to be the rate determining step of the process and as a result of this the catalyst surface acid-base properties should be of importance, as basic surface $\mathrm{O}^{2-}$ ions are more likely to successfully abstract the acidic $\alpha$-hydrogen. Work conducted by Jacobs et al. [11] has shown that the surface of spinels is predominantly made up of exposed octahedral sites. Therefore, based on the mechanism proposed it is most likely that the $\mathrm{Fe}^{3+}$ cations which form the active site are present in octahedral holes. However, there is no evidence in the literature indicating that this is indeed the case. In this study we will examine a series of ferrites for 1-butene ODH to determine whether we can specify a structure-function relationship.

\section{Experimental}

X-ray Photoelectron Spectroscopy (XPS) was performed at the National EPSRC XPS Users' Service (NEXUS) at Newcastle University, an EPSRC Mid-Range Facility. Measurements were performed on a Thermo Scientfic Theta Probe, with a Microfocused monochromatic AlK $\alpha$ source. Data was acquired with pass energy of $40 \mathrm{eV}$ and data analysis was performed using CasaXPS software. The degree of inversion for a ferrite was calculated as the I factor as shown in equation.

Equation for calculation of $I$ factor.

$$
I=\frac{\left(\text { Area of } \mathrm{Fe}_{T}^{3+} 2 p_{\frac{3}{2}} \text { Peak }\right)}{\left(\text { Area of } F e_{T}^{3+} 2 p_{\frac{3}{2}} \text { Peak }+ \text { Area of } \mathrm{Fe}_{O}^{3+} 2 p_{\frac{3}{2}} \text { Peak }\right)} \times 100
$$

Surface area, pore volume and pore diameter measurements were conducted on a Micrometrics Gemini II 2375 Surface Area Analyser at $77 \mathrm{~K}$. A sample of catalyst (typically $0.03-0.05 \mathrm{~g}$ ) was accurately weighed, added to a glass sample tube and degassed in nitrogen overnight at a temperature of $383 \mathrm{~K}$. The sample was then re-weighed and the measurement taken.

Thermogravimetric analysis (TGA) was performed on a SDT Q600 series combined TGA/DSC instrument with an online ESS Evolution Mass Spectrometer. For temperature programmed oxidation (TPO) and temperature programmed reduction (TPR), catalyst samples (approximately $0.005 \mathrm{~g}$ ) were heated from ambient to $1273 \mathrm{~K}$ at a ramp rate of $10 \mathrm{deg} \mathrm{min}^{-1}$ under a $2 \%$ oxygen balance argon mixture (TPO) or a $5 \%$ hydrogen balance nitrogen mixture (TPR) at a flow rate of $100 \mathrm{ml} \mathrm{min}^{-1}$, whilst mass spectrometry data was collected simultaneously. The mass spectrometer then recorded data for fragments including $\mathrm{m} / \mathrm{e} 16,18,28$ and 44 , monitoring $\mathrm{CH}_{4}, \mathrm{H}_{2} \mathrm{O}, \mathrm{CO}$ and $\mathrm{CO}_{2}$ respectively.

$\mathrm{FeCl}_{3} \cdot 6 \mathrm{H}_{2} \mathrm{O}$ (Alfa Aesar) and $\mathrm{XCl}_{2}$ (where $\mathrm{X}=\mathrm{Zn}$ (Alfa Aesar), $\mathrm{Mg}, \mathrm{Mn}, \mathrm{Ni}$ and $\mathrm{Cu}$ (all Sigma Aldrich)) were each dissolved in $500 \mathrm{ml}$ of deionized water. The $\mathrm{XCl}_{2}$ solution was then added quickly to the $\mathrm{FeCl}_{3} \cdot 6 \mathrm{H}_{2} \mathrm{O}$ solution and the resulting mixture stirred vigorously for $30 \mathrm{~min}$. $\mathrm{NaOH}$ (Sigma Aldrich) was added in small portions to 31 of deionized water until completely dissolved. Once all three compounds were in solution, the mixed metal precursor solution was added to the $\mathrm{NaOH}$ solution with rapid stirring. The resultant precipitate slurry was left to stir overnight. The following day the mixture was decanted and centrifuged for $30 \mathrm{~min}$ at $2700 \mathrm{rpm}$. After centrifugation the $\mathrm{pH}$ of the precipitant solution was measured with a Thermo Fisher Orion Starr A111 pH probe, decanted and washed with deionised water. The system of washing and decanting was repeated until a neutral $\mathrm{pH}$ was obtained. The catalyst was then dried at $448 \mathrm{~K}$ for $16 \mathrm{~h}$, crushed and sieved to produce a size of between 250 and $450 \mu \mathrm{m}$ before being calcined at $748 \mathrm{~K}$ for 4 h. In this way $\mathrm{ZnFe}_{2} \mathrm{O}_{4}, \mathrm{MgFe}_{2} \mathrm{O}_{4}, \mathrm{MnFe}_{2} \mathrm{O}_{4}, \mathrm{NiFe}_{2} \mathrm{O}_{4}$, and $\mathrm{CuFe}_{2} \mathrm{O}_{4}$ were prepared.

The catalysts produced were used for 1-butene oxidative dehydrogenation in a continuous-flow fixed-bed reactor at ambient pressure. The reactor tube (glass-lined, $0.95 \mathrm{~cm}$ o.d.) was packed with fused alumina chips with a $1 \mathrm{~cm}^{3}$ catalyst bed in the centre. A constant volume was used to ensure a constant GHSV for comparative purposes. No conversion was observed from experiments with only the fused alumina. The catalyst was heated to $743 \mathrm{~K}$ under a flow of $20 \% \mathrm{O}_{2} / \mathrm{Ar}\left(37.5 \mathrm{~cm}^{3} \mathrm{~min}^{-1}\right)$ and held at temperature for $1 \mathrm{~h}$. The reactor was then cooled to $693 \mathrm{~K}$ and flows of 1-butene $\left(10 \mathrm{~cm}^{3} \mathrm{~min}^{-1}\right)$ and steam $\left(150 \mathrm{~cm}^{3} \mathrm{~min}^{-1}\right)$ were introduced. The steam was produced by pumping an appropriate flow of water with an HPLC pump through a vaporiser. The molar ratio of components in the $\mathrm{ODH}$ gas feed was 
0.75:1:15 oxygen:1-butene:steam with an overall GHSV of $10,050 \mathrm{~h}^{-1}$. The reaction was run for approximately $80 \mathrm{~h}$. The gaseous eluent from the reactor entered a knockout pot where water was condensed. Dry gaseous samples were subsequently analysed by on-line gas chromatography using a Thermo Scientific Focus Gas Chromatograph equipped with a Flame Ionisation Detector and a Chrompack sodium sulfate on alumina column. GC analysis of the water confirmed only trace levels of dissolved hydrocarbons. The absence or otherwise of carbon dioxide $(<0.5 \%$ yield) was confirmed by mass spectrometry.

Selectivity and conversion were calculated as outlined in Eqs. 1 and 2.

Equation 1: Equation for calculation of conversion.

Conversion $(C)=\frac{(\text { mol } n-\text { butene in })-(\text { mol } n-\text { butene out })}{\text { moln }- \text { butene out }} \times 100$

Equation 2: Equation for calculation of selectivity of product $\mathrm{X}$.

\section{Selectivity of product $X(S)$}

$$
=\frac{\text { mol product } X}{(\text { moln }- \text { butene } i n)-(\text { moln }- \text { butene out })} \times 100
$$

Yield of a product $(\mathrm{Y})$ was calculated by $\mathrm{Y}=\mathrm{C} * \mathrm{~S}$.

\section{Results}

Zinc ferrite, manganese ferrite, nickel ferrite, copper ferrite and magnesium ferrite were all prepared as described in the Experimental section. The materials were characterised by Raman spectroscopy, XRD and EPR spectroscopy and the results are detailed in the supplementary information. All characterisation results confirmed the production of nanosized particles of the appropriate ferrite consistent with the literature. BET surface area data for the various $\mathrm{A}^{2+}$ metal ferrites showed a wide variation (Table 1) with $\mathrm{MnFe}_{2} \mathrm{O}_{4}$ and $\mathrm{MgFe}_{2} \mathrm{O}_{4}$ showing considerably higher surface areas and lower average pore diameters than any of the other ferrites.

Table 1 BET surface area, pore diameters and pore volumes for $\mathrm{AFe}_{2} \mathrm{O}_{4}$ materials

\begin{tabular}{llll}
\hline Sample & $\begin{array}{l}\text { Surface area } \\
\left(\mathrm{m}^{2} \mathrm{~g}^{-1}\right)\end{array}$ & $\begin{array}{l}\text { Average pore } \\
\text { diameter }(\mathrm{nm})\end{array}$ & $\begin{array}{l}\text { Total pore vol- } \\
\text { ume }\left(\mathrm{cm}^{3} \mathrm{~g}^{-1}\right)\end{array}$ \\
\hline $\mathrm{MnFe}_{2} \mathrm{O}_{4}$ & 203 & 6.0 & 0.33 \\
$\mathrm{MgFe}_{2} \mathrm{O}_{4}$ & 206 & 3.9 & 0.22 \\
$\mathrm{CuFe}_{2} \mathrm{O}_{4}$ & 56 & 15.5 & 0.20 \\
$\mathrm{ZnFe}_{2} \mathrm{O}_{4}$ & 56 & 12.0 & 0.18 \\
$\mathrm{NiFe}_{2} \mathrm{O}_{4}$ & 82 & 15.5 & 0.30 \\
$\mathrm{Fe}_{3} \mathrm{O}_{4}$ & 1 & 53.7 & 0.01 \\
\hline
\end{tabular}

$\mathrm{Cu}, \mathrm{Zn}$ and $\mathrm{Ni}$ ferrites showed moderate surface areas. In contrast commercial $\mathrm{Fe}_{3} \mathrm{O}_{4}$ revealed an extremely low surface area and high average pore diameter.

\subsection{Thermogravimetric Analysis (TGA)}

TGA measurements were taken for each of the metal ferrites in a $5 \% \mathrm{H}_{2} / \mathrm{N}_{2}$ flow (shown in supplementary material) to determine how they behaved in a reducing environment at reaction temperature as a means of probing oxygen lability of each ferrite. All of the catalysts tested exhibited a weight loss below $400 \mathrm{~K}$, corresponding to the loss of adsorbed water from the catalyst surface. The weight loss between 400 and $693 \mathrm{~K}$ (reaction temperature) and the theoretical number of oxygen atoms lost per molecule were calculated and are detailed in Table 2. In all the catalysts tested it was observed that reduction had occurred to some extent below ODH reaction temperature $(693 \mathrm{~K})$. The theoretical number of $\mathrm{O}$ atoms lost from each molecule during the reduction was calculated to give a measure of the oxygen lability for each of the ferrites. Based on the Mars-van Krevelen mechanism, where oxygen is being continuously removed as water and replaced by gaseous oxygen, it may be expected that oxygen lability would play a big role in catalyst activity. Percentage weight data was set to $100 \%$ at $400 \mathrm{~K}$ in order to remove any variation due to loss of adsorbed water. Based on the results from these TPR experiments it was found that $\mathrm{CuFe}_{2} \mathrm{O}_{4}$ had the highest oxygen lability.

\subsection{Analysis by XPS}

XPS was carried out on $\mathrm{ZnFe}_{2} \mathrm{O}_{4}, \mathrm{MnFe}_{2} \mathrm{O}_{4}, \mathrm{MgFe}_{2} \mathrm{O}_{4}$, $\mathrm{CuFe}_{2} \mathrm{O}_{4}$ and $\mathrm{NiFe}_{2} \mathrm{O}_{4}$. Element spectra are reported in the supplementary data, Figs. 5S-19S. Interpretation of the XPS spectra allowed the relative amounts of each atom on the catalyst surface to be determined and allowed an approximate inversion parameter to be calculated (Table 3 ).

The Fe $2 \mathrm{p}_{3 / 2}$ peak for each of the ferrites occurs at a binding energy of $\sim 710 \mathrm{eV}$, indicative of a trivalent Fe cation [12]. Upon refinement, it was shown that the Fe $2 p_{3 / 2}$ peak

Table 2 Loss of oxygen between 400 and $693 \mathrm{~K}$ under reducing conditions

\begin{tabular}{lll}
\hline Catalyst & Mass loss (\%) & $\begin{array}{l}\text { O atoms lost/ } \\
\text { molecular unit }\end{array}$ \\
\hline $\mathrm{ZnFe}_{2} \mathrm{O}_{4}$ & 1.5 & 0.2 \\
$\mathrm{MnFe}_{2} \mathrm{O}_{4}$ & 6.5 & 0.9 \\
$\mathrm{MgFe}_{2} \mathrm{O}_{4}$ & 1.8 & 0.2 \\
$\mathrm{CuFe}_{2} \mathrm{O}_{4}$ & 9.7 & 1.5 \\
$\mathrm{NiFe}_{2} \mathrm{O}_{4}$ & 4.8 & 0.7 \\
$\mathrm{Fe}_{3} \mathrm{O}_{4}$ & 1.1 & 0.2 \\
\hline
\end{tabular}


Table 3 Pre-reaction XPS results for catalysts varied $\mathrm{A}^{2+}$ metal ferrites, where $I$ factor represents the percentage of $\mathrm{Fe}^{3+}$ present in tetrahedral holes

\begin{tabular}{lllllll}
\hline Sample & $\begin{array}{l}\text { Target Fe/A } \\
\text { ratio }\end{array}$ & $\begin{array}{l}\mathrm{A}^{2+} \\
\text { (Atom\%) }\end{array}$ & $\begin{array}{l}\mathrm{Fe}^{3+} \\
\text { (Atom\%) }\end{array}$ & $\begin{array}{l}\mathrm{O}^{2-} \\
\text { (Atom\%) }\end{array}$ & $\begin{array}{l}\text { Measured Fe/A } \\
\text { Ratio }\end{array}$ & I factor (\%) \\
\hline $\mathrm{MnFe}_{2} \mathrm{O}_{4}$ & 2.0 & 10.5 & 19.1 & 70.4 & 1.8 & 40 \\
$\mathrm{MgFe}_{2} \mathrm{O}_{4}$ & 2.0 & 14.5 & 19.0 & 66.5 & 1.3 & 39 \\
$\mathrm{CuFe}_{2} \mathrm{O}_{4}$ & 2.0 & 7.1 & 25.2 & 67.7 & 3.5 & 71 \\
$\mathrm{NiFe}_{2} \mathrm{O}_{4}$ & 2.0 & 7.2 & 23.9 & 68.9 & 3.3 & 52 \\
$\mathrm{ZnFe}_{2} \mathrm{O}_{4}$ & 2.0 & 4.9 & 24.3 & 70.8 & 5.0 & 21 \\
\hline
\end{tabular}

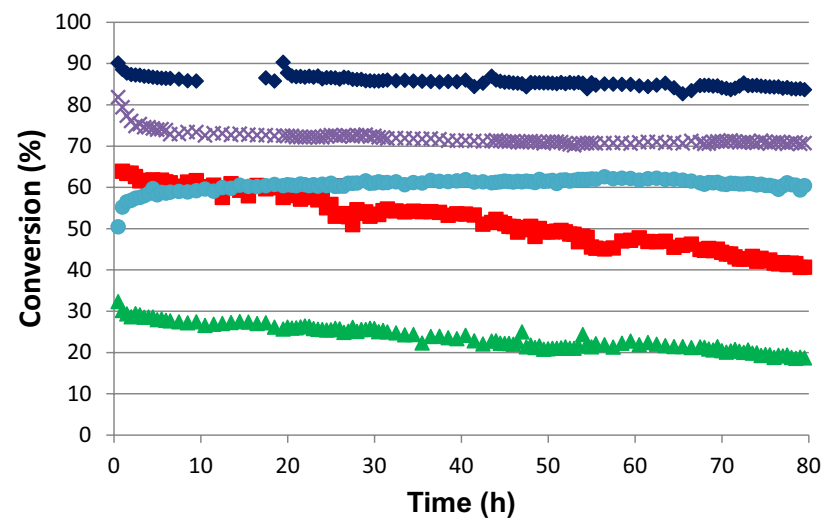

- $\mathrm{ZnFe} 2 \mathrm{O} 4$ agFe2O4 $\triangle \mathrm{CuFe} 2 \mathrm{O} 4 \times \mathrm{NiFe} 2 \mathrm{O} 4 \bullet \mathrm{MnFe} 2 \mathrm{O} 4$

Fig. 1 Conversion of 1-butene at $693 \mathrm{~K}$ with a molar ratio of 0.75:1:15 oxygen:1-butene:steam and an overall GHSV of 10,050 $\mathrm{h}^{-1}$

could be fitted to two overlapping peaks, rather than a single peak. This suggests that the $\mathrm{Fe}^{3+}$ ions in each of the catalysts were present in two differing environments, octahedral and tetrahedral holes [13]. These peaks were then used to calculate an estimated inversion parameter based on the area under the lower binding energy octahedral $\mathrm{Fe}^{3+}$ relative to the area under the higher binding energy tetrahedral $\mathrm{Fe}^{3+}$ peak. The inversion parameters calculated for each of the ferrites indicates that they are all random spinel structures, with $\mathrm{CuFe}_{2} \mathrm{O}_{4}$ showing the highest inversion parameter. This is in agreement with work carried out by Lee et al. [7] on metal ferrites, where it was found that based on XPS measurements the spinel structure, observed in metal ferrites of $\mathrm{Zn}, \mathrm{Mn}, \mathrm{Mg}, \mathrm{Cu}$ and $\mathrm{Ni}$, was random.

\subsection{Reaction Testing}

The catalysts were all tested for activity and selectivity to produce 1,3-butadiene under standard conditions (693 K, 0.75:1:15 oxygen:1-butene:steam, GHSV $10,050 \mathrm{~h}^{-1}$ ). The conversions and 1,3-butadiene yields are shown in Figs. 1 and 2. Of the metal ferrites tested $\mathrm{ZnFe}_{2} \mathrm{O}_{4}$ was shown to have the highest 1-butene conversion over the period of testing. $\mathrm{Fe}_{3} \mathrm{O}_{4}$ was unstable under reaction conditions and converted to $\mathrm{Fe}_{2} \mathrm{O}_{3}$, which gave poor activity and selectivity

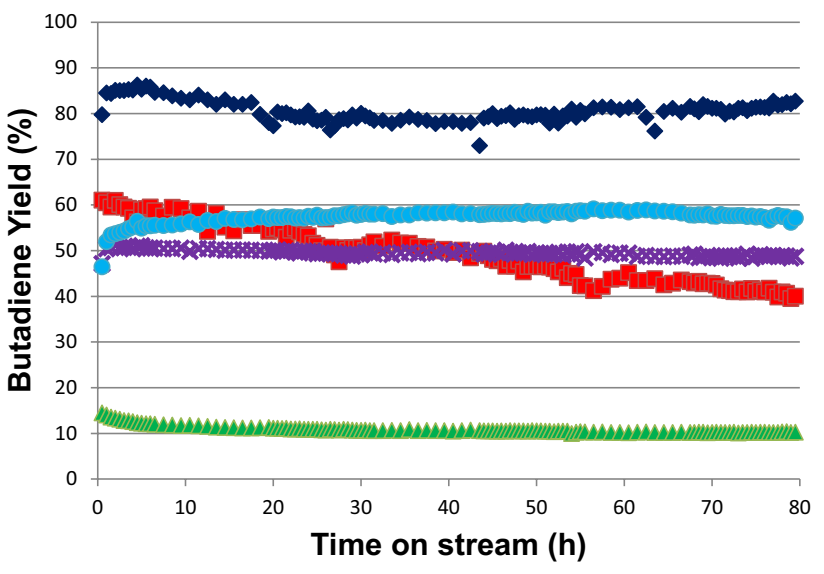

$\bullet \mathrm{ZnFe} 2 \mathrm{O} 4 \quad \mathrm{MgFe} 2 \mathrm{O} 4 \Delta \mathrm{CuFe} 2 \mathrm{O} 4 \times \mathrm{NiFe} 2 \mathrm{O} 4 \cdot \mathrm{MnFe} 2 \mathrm{O} 4$

Fig. 2 1,3-butadiene yield over $\mathrm{AFe}_{2} \mathrm{O}_{4}$ catalysts. Conditions: $693 \mathrm{~K}$ with a molar ratio of $0.75: 1: 15$ oxygen:1-butene:steam and an overall GHSV of $10,050 \mathrm{~h}^{-1}$

$[14,15]$. The 1-butene conversion decreased in the order $\mathrm{Zn}>\mathrm{Ni}>\mathrm{Mg}=\mathrm{Mn}>\mathrm{Cu}>\mathrm{Fe}$ after $20 \mathrm{~h}$ on-stream and $\mathrm{Zn}>\mathrm{Ni}>\mathrm{Mn}>\mathrm{Mg}>\mathrm{Cu}>\mathrm{Fe}$ after $80 \mathrm{~h}$ on stream.

Isomerisation products, cis and trans-2-butene, were observed in the product stream for each of the catalyst runs. $\mathrm{ZnFe}_{2} \mathrm{O}_{4}, \mathrm{MnFe}_{2} \mathrm{O}_{4}, \mathrm{MgFe}_{2} \mathrm{O}_{4}, \mathrm{NiFe}_{2} \mathrm{O}_{4}$ (and $\mathrm{Fe}_{3} \mathrm{O}_{4} /$ $\mathrm{Fe}_{2} \mathrm{O}_{3}$ not shown) all show low isomer yields $<10 \%$ for each isomer throughout time on stream. However, $\mathrm{CuFe}_{2} \mathrm{O}_{4}$ shows much higher isomer selectivities, $30 \%$ for cis-2-butene and $\sim 20 \%$ for trans-2-butene, making it a moderately good isomerization catalyst. The deactivation observed with any of the catalysts relates to the loss of isomerisation activity in contrast to 1,3-butadiene yield which remains constant. No equilibrium is achieved between the butene isomers over any catalyst.

All the catalysts gave a mass balance $(100 \pm 5 \%)$ however with $\mathrm{NiFe}_{2} \mathrm{O}_{4}$ the mass balance revealed that the products detected could only account for a total selectivity of $\sim 80 \%$. Using mass spectrometry data collected throughout time on stream a notable increase in the ion current for the fragment associated with $\mathrm{CO}_{2}$ was observed immediately as the reaction started confirming that $\mathrm{CO}_{2}$ 


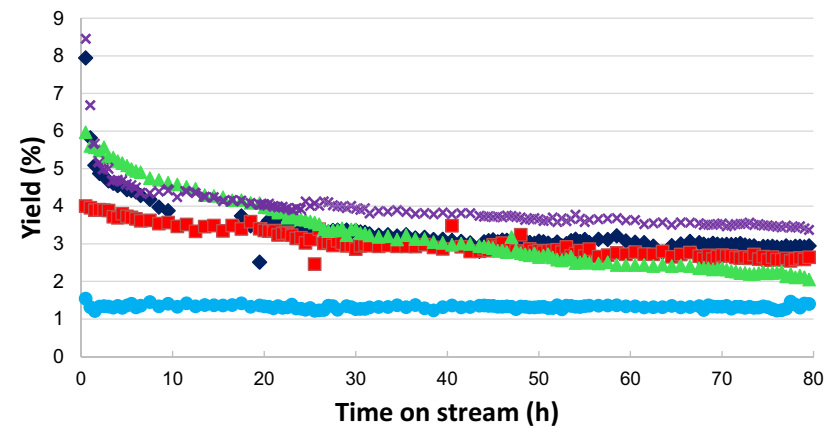

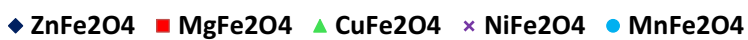

Fig. 3 Yield of trans-2-butene over $\mathrm{AFe}_{2} \mathrm{O}_{4}$ catalysts. Conditions: $693 \mathrm{~K}$ with a molar ratio of $0.75: 1: 15$ oxygen:1-butene:steam and an overall GHSV of $10,050 \mathrm{~h}^{-1}$

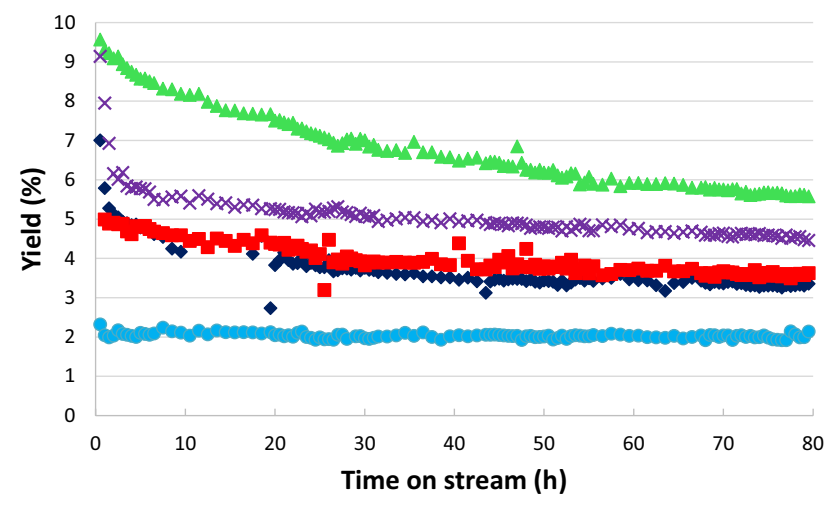

- ZnFe2O4 - MgFe2O4 $\triangle \mathrm{CuFe2O4} \times \mathrm{NiFe2O4} \bullet \mathrm{MnFe2O}$

Fig. 4 Yield of cis-2-butene over $\mathrm{AFe}_{2} \mathrm{O}_{4}$ catalysts. Conditions: $693 \mathrm{~K}$ with a molar ratio of $0.75: 1: 15$ oxygen:1-butene:steam and an overall GHSV of $10,050 \mathrm{~h}^{-1}$

was being produced. No carbon dioxide was detected with any other metal ferrite (Figs. 3, 4).

\subsection{Post Reaction Characterization}

The catalysts were characterized by EPR spectroscopy, Raman spectroscopy, XRD, BET and TPO after use. EPR spectroscopy, XRD and Raman spectroscopy confirmed that the materials had retained their integrity (Supplementary material). BET analysis however revealed a significant loss in surface area (Table 4) for all catalysts. Post reaction TPO profiles from each of the catalysts were obtained, all exhibited evolution of $\mathrm{CO}_{2}$, indicating a degree of carbon laydown on the catalysts.
Table 4 Post-reaction BET surface areas for $\mathrm{A}^{2+}$ metal ferrite catalysts

\begin{tabular}{lllll}
\hline Sample & $\begin{array}{l}\text { Surface } \\
\text { area } \\
\left(\mathrm{m}^{2} \mathrm{~g}^{-1}\right)\end{array}$ & $\begin{array}{l}\text { Average pore } \\
\text { diameter }(\mathrm{nm})\end{array}$ & $\begin{array}{l}\text { Total pore vol- } \\
\text { ume }\left(\mathrm{cm}^{3} \mathrm{~g}^{-1}\right)\end{array}$ & $\begin{array}{l}\% \text { Sur- } \\
\text { face area } \\
\text { loss }\end{array}$ \\
\hline $\mathrm{ZnFe}_{2} \mathrm{O}_{4}$ & 11 & 38.8 & 0.09 & 75 \\
$\mathrm{MnFe}_{2} \mathrm{O}_{4}$ & 37 & 28.3 & 0.27 & 95 \\
$\mathrm{MgFe}_{2} \mathrm{O}_{4}$ & 94 & 10.8 & 0.28 & 54 \\
$\mathrm{CuFe}_{2} \mathrm{O}_{4}$ & 27 & 28.1 & 0.16 & 52 \\
$\mathrm{NiFe}_{2} \mathrm{O}_{4}$ & 52 & 18.3 & 0.28 & 37 \\
\hline
\end{tabular}

Of these catalysts, only $\mathrm{MgFe}_{2} \mathrm{O}_{4}$ exhibited evidence of carbon laydown in its Raman spectra, a peak at $1580 \mathrm{~cm}^{-1}$, corresponding to graphitic carbon laydown.

\section{Discussion}

Extensive characterisation of the ferrites is reported in the Supplementary Data and compared with data from the literature. Nanocrystalline ferrites give unique characterisation fingerprints and from the initial characterisation by AAS, XRD, Raman spectroscopy and EPR it is clear that nanocrystallites of the five ferrites were produced. The XRD revealed that the catalysts were not highly crystalline, which is an important parameter as a lack of highly crystalline material has been shown to be a key factor in the production of an active catalyst [2], as a highly crystalline form inhibits oxygen mobility. XPS revealed that the surface $\mathrm{Fe}: \mathrm{A}^{2+}$ ratio of the ferrites did not match the bulk. Of the four catalysts $\mathrm{MnFe}_{2} \mathrm{O}_{4}$ showed the best correlation between bulk and surface $\mathrm{Fe} / \mathrm{A}^{2+}$ ratio, as well as the closest overall $\mathrm{Fe} / \mathrm{A}^{2+}$ ratio to the target ratio of two. $\mathrm{MgFe}_{2} \mathrm{O}_{4}$ showed a much lower Fe/ $\mathrm{A}^{2+}$ ratio, whilst $\mathrm{CuFe}_{2} \mathrm{O}_{4}, \mathrm{NiFe}_{2} \mathrm{O}_{4}$ and $\mathrm{ZnFe}_{2} \mathrm{O}_{4}$ showed much higher ratios than observed in the bulk. These results are in agreement with results on cobalt ferrites by Ballarini et al. [16], who showed that at smaller crystallite sizes the (111) crystal phase termination was dominant, which was shown to have a higher Fe content than the (110) or (100) and hence an increased $\mathrm{Fe} / \mathrm{A}^{2+}$ ratio was observed for the ferrite surface. Based on literature examples, the XPS peaks for each of the $\mathrm{A}^{2+}$ ions were typical of XPS peaks for each of the ions incorporated into a metal ferrite, $\mathrm{Zn}$ [17], Mn [18], $\mathrm{Mg}$ [19], $\mathrm{Cu}$ [20] and Ni [21]. The main XPS peaks in the $\mathrm{O} 1 \mathrm{~s}$ region were shown to occur at a binding energy of $\sim 529 \mathrm{eV}$ for $\mathrm{Zn}, \mathrm{Mn}, \mathrm{Mg}$, and Ni ferrites and at $~ 532 \mathrm{eV}$ for $\mathrm{Cu}$ ferrite. All of the $\mathrm{O} 1 \mathrm{~s}$ spectra of the ferrites tested had a secondary peak at approximately $\sim 2.5 \mathrm{eV}$ higher than the main peak. This peak has been assigned to the presence of $\mathrm{OH}$ on the catalyst surface [22]. There was also the presence of a third peak in the $\mathrm{O} 1 \mathrm{~s}$ spectra of $\mathrm{MnFe}_{2} \mathrm{O}_{4}$ and $\mathrm{CuFe}_{2} \mathrm{O}_{4}$, which occurred at a binding energy $3 \mathrm{eV}$ higher and $1.8 \mathrm{eV}$ 
lower than the main O1s peaks respectively. In work carried out by Zhang et al. [18] and Kester et al. [23] researching $\mathrm{MnFe}_{2} \mathrm{O}_{4}$ and $\mathrm{CuFe}_{2} \mathrm{O}_{4}$ respectively they also found three peaks in the O1s region of the XPS spectrum at very similar binding energies to those observed in this work, they assigned the additional peaks to oxygen present as water and organic contaminants present on the ferrite surface. Therefore, our XPS results are consistent with the literature. The inversion parameter determined from XPS revealed that the small nano-crystallite ferrites have significantly different values from that expected from bulk samples. This behaviour has also been observed in the literature [24-27]. For example, with zinc ferrite, as the particle size of the crystallite decreases the inversion parameter can increase from 4 to $43 \%$ leading to an increase in $\mathrm{Fe}^{3+}(\mathrm{A})-\mathrm{O}^{2-}-\mathrm{Fe}^{3+}(\mathrm{B})$ interactions [27].

Over the course of the testing the surface area of all the ferrites decreased. Zinc and manganese ferrites lost $~ 80 \%$ of their surface area, while magnesium and copper ferrites lost around 50\%. Nickel ferrite in contrast, lost only $37 \%$ of its initial surface area during reaction. The change in the EPR spectra (Supplementary data) was also consistent with an increase in particle size for all the ferrites. Surprisingly the BET surface area of ferrite catalysts is rarely reported in the literature and even then only pre-reaction [2], so there is little data in the literature to compare with our data. Nevertheless, these are significant losses in surface area, which are due to the presence of steam in the feed [14], yet the loss in area is not reflected in any equivalent loss of activity indicating no direct link between surface area and activity [5]. Even so, activity is not constant with most of the samples tested. Slow deactivation was evident with zinc ferrite and nickel ferrite, while more significant deactivation was observed for magnesium and copper ferrites. Manganese ferrite displayed no loss in activity. Only with magnesium ferrite was the loss in activity in any way similar to the loss in surface area. However, on closer examination of the deactivation process it is clear that the yield of 1,3-butadiene does not decrease significantly (Fig. 2) except for magnesium ferrite, while for the rest of the catalysts, butadiene yield is relatively constant, suggesting that the loss of activity is related to the isomerisation process and that the isomerisation site and the dehydrogenation site are different. Isomerisation normally occurs over acid sites and indeed it has been shown that butene isomerisation is linked to acidity over ferrites [28].

Testing of the ferrites revealed significant differences in activity and selectivity with zinc ferrite showing the highest butadiene yield. In general, the literature agrees that $\mathrm{ZnFe}_{2} \mathrm{O}_{4}$ is the best metal ferrite for 1-butene ODH. A study by Lee et al. [7] on modifying the $\mathrm{A}^{2+}$ cation in metal ferrites for 1-butene $\mathrm{ODH}$ found a strong dependence on $\mathrm{A}^{2+}$. Although they observed fairly similar 1-butene conversion results, they observed lower conversions for $\mathrm{ZnFe}_{2} \mathrm{O}_{4}$ and
$\mathrm{NiFe}_{2} \mathrm{O}_{4}$ and only reported the results at a single time point, after $6 \mathrm{~h}$ on stream. Nevertheless, the activity of the metal ferrites gave the following order, $\mathrm{ZnFe}_{2} \mathrm{O}_{4}>\mathrm{MgFe}_{2} \mathrm{O}_{4}>\mathrm{M}$ $\mathrm{nFe}_{2} \mathrm{O}_{4}>\mathrm{NiFe}_{2} \mathrm{O}_{4}>\mathrm{CoFe}_{2} \mathrm{O}_{4}>\mathrm{CuFe}_{2} \mathrm{O}_{4}$ [7]. In contrast, a recent report [29] indicated that zinc ferrite had the lowest conversion for 1-butene oxidative dehydrogenation, while nickel ferrite had the highest conversion. However, no selectivity data was reported and the feed used contained no steam [29] making comparison difficult. One clear difference between the ferrites tested in our study was the production of carbon dioxide from nickel ferrite. No other ferrite produced carbon dioxide and hence we suggest that carbon dioxide is produced on a nickel site rather than an iron site. Nickel oxide is a well-known oxidation catalyst [30] and the addition of nickel to $\mathrm{Bi}-\mathrm{Mo}$ catalyst for 1-butene ODH [31] revealed that as the amount of nickel was increased the amount of carbon dioxide produced was also increased. The nickel XPS shows potentially the presence of $\mathrm{Ni}^{3+}$, which would likely be involved in any over-oxidation to carbon dioxide [32]. Carbon dioxide production from nickel ferrite was also observed in a study by Kiyokawa and Ikenaga [33].

The thermodynamic equilibrium for the butenes at $\sim 673 \mathrm{~K}$ is approximately $1: 1: 1$, therefore it may be expected that the cis:trans ratio would be $\sim 1$ as there should be an equal propensity to form either isomer from 1-butene. The cis:trans ratio is shown in Fig. 5 and it can be seen that the ratio is almost always above 1 indicating that the yield of cis-2-butene was always higher than the yield of trans-2-butene. This may indicate that there are separate sites for isomerisation of 1-butene to trans-2-butene and 1-butene to cis-2-butene or that both isomers are formed equally but trans-2-butene reacts faster to form butadiene than cis-2-butene and that there is no detectable cis/trans isomerisation within the residence time of the reactants in the catalyst bed. The ratio does appear to depend to a limited degree on the extent of deactivation. Manganese

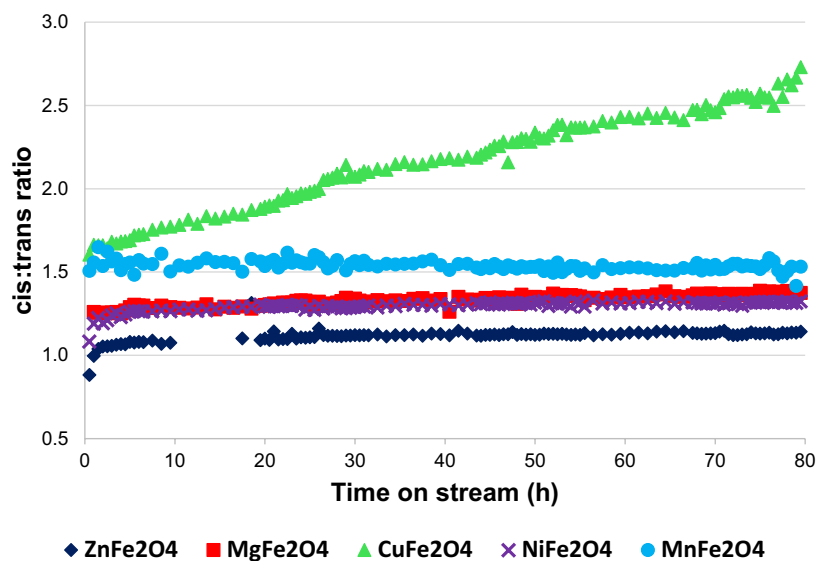

Fig. 5 Cis-2-butene:trans-2-butene ratio against time on stream 
ferrite shows no deactivation and a steady cis:trans ratio is obtained. However, the change in cis:trans ratio observed for copper ferrite is markedly different from the other ferrites. The butadiene yield from copper ferrite is low but shows no significant change over the majority of the time on stream (Fig. 2), therefore the change in cis:trans ratio is not due to changes in the rate of conversion of the butenes to butadiene. Rather it must be due to changes in the rate of isomerisation to each isomer implying that isomerisation between 1-butene and cis-2-butene and 1-butene and trans-2-butene are independent and that there is no cis/trans isomerisation within the residence time in the reactor. This may relate to the acid/ base nature of the ferrite surface. It has been shown that isomerization of 1-butene can be used as a test reaction for the acid/basic character of a solid [34]. With solid acid catalysis the mechanism involves a 2-butyl cation intermediate, whereas with solid base catalysis the mechanism involves a $\pi$-allyl intermediate. The effect of the different mechanisms can be seen in the cis-2- butene:trans-2-butene ratio, e.g. a cis:trans ratio less than 1.0, favouring the trans-isomer, indicates acid behaviour, while a ratio higher than 3 , favouring the $c i s$-isomer, indicates base behaviour. Our values suggest both acid and base mechanisms are operating. In a study of 1-butene ODH over copper ferrite supported on activated carbon, using lattice oxygen to react with a 1-butene/Ar feed followed by $\mathrm{O}_{2} / \mathrm{Ar}$ regeneration [33], significant isomerisation was observed that also favoured cis-2-butene, albeit at a lower temperature $543 \mathrm{~K}$. The results also indicated that isomerisation and oxidative dehydrogenation did not take place on the same site [33], which is consistent with our results.

Given that the $\mathrm{A}^{2+}$ ion is not directly linked to the reaction mechanism, a ferrite surface with increased proportions of $\mathrm{Fe}^{3+}$ and $\mathrm{O}^{2-}$ present on the catalyst surface, as observed in $\mathrm{ZnFe}_{2} \mathrm{O}_{4}, \mathrm{NiFe}_{2} \mathrm{O}_{4}$ and $\mathrm{CuFe}_{2} \mathrm{O}_{4}$, might be expected to yield enhanced catalytic activity in a 1-butene ODH reaction based on the mechanism suggested by Finocchio et al. [35], which indicates that the reaction takes place on an $\mathrm{Fe}$ and $\mathrm{O}$ rich surface. However the 1,3-butadiene yield from $\mathrm{ZnFe}_{2} \mathrm{O}_{4}, \mathrm{NiFe}_{2} \mathrm{O}_{4}$ and $\mathrm{CuFe}_{2} \mathrm{O}_{4}$, was $\sim 80 \%, 50 \%$ and $10 \%$ respectively showing no obvious linkage with surface $\mathrm{Fe}: \mathrm{A}^{2+}$ ratio. One aspect that must be considered is the extent of interchange of the $\mathrm{A}^{2+}$ and $\mathrm{Fe}^{3+}$ ions between tetrahedral and octahedral holes. Three types of spinel structure have been defined: normal, random and inverse. Normal spinel structure has oxygen ions in a face centred cubic close packed lattice with $\mathrm{A}^{2+}$ ions filling $1 / 8$ th of the tetrahedral holes and the $\mathrm{B}^{3+}$ ions occupying half of the octahedral holes. In the inverse spinel structure $\mathrm{B}^{3+}$ ions occupy tetrahedral holes with a 1:1 mixture of $\mathrm{A}^{2+}$ and $\mathrm{B}^{3+}$ ions occupy the octahedral holes. As might be expected the random spinel structure has $\mathrm{A}^{2+}$ and $\mathrm{B}^{3+}$ ions distributed randomly between octahedral and tetrahedral

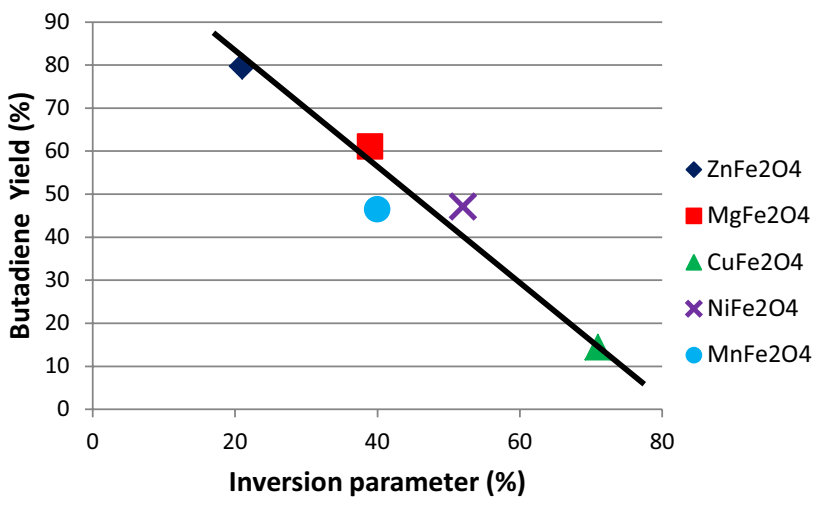

Fig. 6 Relationship between inversion parameter and butadiene yield holes [36]. In the bulk state copper and nickel ferrites are inverse spinels, while zinc ferrite is a normal spinel. Magnesium ferrite is close to an inverse spinel with an inversion factor of 0.9 , while manganese ferrite is close to a random spinel with an inversion parameter of 0.2 . However recent literature has shown that at small particle sizes $(<100 \mathrm{~nm})$ there can be changes to the inversion parameter as the particle size gets smaller [24, 27, 37, 38]. Using the XPS iron signal, inversion parameters were determined for the catalysts (Table 3), when these values were plotted against butadiene yield a straight-line correlation was obtained as shown in Fig. 6. This suggests that it is not just $\mathrm{Fe}^{3+}$ that is the key species for oxidative dehydrogenation but that the $\mathrm{Fe}^{3+}$ must be in an octahedral hole. As the occupancy of $\mathrm{Fe}^{3+}$ decreases so 1,3-butadiene yield decreases. At the single catalyst level however, the correlation is not well defined, for example magnesium ferrite and manganese ferrite have similar inversion parameters but manganese ferrite records a lower butadiene yield than expected. Nevertheless a similar plot for isomerisation shows no correlation indicating different sites for oxidative dehydrogenation and isomerisation.

\section{Conclusions}

All the ferrites tested were active for $\mathrm{ODH}$ and gave an order of activity after $80 \mathrm{~h}$ on-stream of $\mathrm{ZnFe}_{2} \mathrm{O}_{4}>\mathrm{N}$ $\mathrm{iFe}_{2} \mathrm{O}_{4}>\mathrm{MnFe}_{2} \mathrm{O}_{4}>\mathrm{MgFe}_{2} \mathrm{O}_{4}>\mathrm{CuFe}_{2} \mathrm{O}_{4}>\mathrm{FeFe}_{2} \mathrm{O}_{4}$. However, $\mathrm{Fe}_{3} \mathrm{O}_{4}$ was unstable under reaction conditions and was converted to $\mathrm{Fe}_{2} \mathrm{O}_{3}$, which showed very low activity. All catalysts lost significant surface area (up to $\sim 80 \%$ ) under reaction conditions of $0.75: 1: 15$ oxygen:1butene:steam at $693 \mathrm{~K}$ but the 1,3-butadiene yield showed no deactivation for all catalysts except $\mathrm{MgFe}_{2} \mathrm{O}_{4}$. Catalyst deactivation was related to loss of isomerisation sites indicating that butene isomerisation and ODH occurred on different sites. Nickel ferrite was the only material that gave 
carbon dioxide as a significant product, possibly related to $\mathrm{Ni}^{3+}$ present in the system, all others were selective to 1,3-butadiene, with zinc ferrite having the highest steadystate yield of $\sim 80 \%$. Inversion parameters were determined for the ferrites from XPS and a correlation was obtained between 1,3-butadiene yield and inversion parameter, suggesting that $\mathrm{Fe}^{3+}$ in an octahedral hole is a key species in the mechanism of oxidative dehydrogenation.

Supplementary Information The online version contains supplementary material available at https://doi.org/10.1007/s11244-021-01426-z.

Acknowledgements The authors would like to acknowledge funding for a studentship for one of us (CB) from INVISTA Intermediates.

\section{Declarations}

Conflict of interest There are no conflicts of interest.

Open Access This article is licensed under a Creative Commons Attribution 4.0 International License, which permits use, sharing, adaptation, distribution and reproduction in any medium or format, as long as you give appropriate credit to the original author(s) and the source, provide a link to the Creative Commons licence, and indicate if changes were made. The images or other third party material in this article are included in the article's Creative Commons licence, unless indicated otherwise in a credit line to the material. If material is not included in the article's Creative Commons licence and your intended use is not permitted by statutory regulation or exceeds the permitted use, you will need to obtain permission directly from the copyright holder. To view a copy of this licence, visit http://creativecommons.org/licenses/by/4.0/.

\section{References}

1. Jung JC, Kim H, Choi AS, Chung Y-M, Kim TJ, Lee SJ, Oh S-H, Song IK (2006) Preparation, characterization, and catalytic activity of bismuth molybdate catalysts for the oxidative dehydrogenation of n-butene into 1,3-butadiene. J Mol Catal A 259:166-170

2. Young-Min Chung Y-M, Kwon Y-T, Kim TJ, Lee SJ, Oh S-H (2009) Factors affect on the reaction performance of the oxidative dehydrogenation of n-butene to 1,3-butadiene over $\mathrm{Zn}$-ferrite catalysts. Catal Lett 130:417-423

3. Gibson MA, Hightower JW (1976) Oxidative dehydrogenation of butenes over magnesium ferrite kinetic and mechanistic studies. J Catal 41:431-439

4. Toledo-Antonio JA, Nava N, Martınez M, Bokhimi X (2002) Correlation between the magnetism of non-stoichiometric zinc ferrites and their catalytic activity for oxidative dehydrogenation of 1-butene. Appl Catal A 234:137-144

5. Lee H, Jung JC, Kim H, Chung Y-M, Kim TJ, Lee SJ, Oh S-H, Kim YS, Song IK (2008) Effect of $\mathrm{pH}$ in the preparation of $\mathrm{ZnFe}_{2} \mathrm{O}_{4}$ for oxidative dehydrogenation of $n$-butene to 1,3-butadiene: correlation between catalytic performance and surface acidity of $\mathrm{ZnFe}_{2} \mathrm{O}_{4}$. Catal Commun 9:1137-1142

6. Kung HH, Kundalkar B, Kung MC, Cheng WH (1980) Selectivity in the oxidative dehydrogenation of butene on zinc-iron oxide catalyst. J Phys Chem 84:382-388

7. Lee H, Jung JC, Kim H, Chung Y-M, Kim TJ, Lee SJ, Oh S-H, Kim YS, Song IK (2008) Effect of divalent metal component
$\left(\mathrm{Me}^{\mathrm{II}}\right)$ on the catalytic performance of $\mathrm{me}^{\mathrm{ii}} \mathrm{fe}_{2} \mathrm{O}_{4}$ catalysts in the oxidative dehydrogenation of n-butene to 1,3 -butadiene. Catal Lett 124:364-368

8. Lee H, Jung JC, Kim H, Chung Y-M, Kim TJ, Lee SJ, Oh S-H, Kim YS, Song IK (2009) Oxidative dehydrogenation of n-butene to 1,3-butadiene over $\mathrm{ZnMe}^{\mathrm{III}} \mathrm{FeO}_{4}$ catalysts: effect of trivalent metal $\left(\mathrm{Me}^{\mathrm{III}}\right)$. Catal Lett 131:344-349

9. Finocchio E, Busca G, Ramis G, Lorenzelli V (1997) On the mechanism of the selective oxy-dehydrogenation of n-butenes to 1,3-butadiene on magnesium ferrite: an FT-IR study. Stud Surf Sci Catal 110:989-998

10. Lee H, Jung JC, Song IK (2009) Oxidative dehydrogenation of $n$-butene to 1,3-butadiene over sulfated $\mathrm{ZnFe}_{2} \mathrm{O}_{4}$ catalyst. Catal Lett 133:321-327

11. Jacobs JP, Maltha A, Reintjes JGH, Drimal J, Ponec V, Brongersma HH (1994) The surface of catalytically active spinels. J Catal 147:294-300

12. Allen GC, Hallam KR (1996) Characterisation of the spinels $\mathrm{M}_{\mathrm{x}} \mathrm{Co}_{1-\mathrm{x}} \mathrm{Fe}_{2} \mathrm{O}_{4}(\mathrm{M}=\mathrm{Mn}, \mathrm{Fe}$ or $\mathrm{Ni})$ using X-ray photoelectron spectroscopy. Appl Surf Sci 93:25-30

13. Li F, Liu X, Yang Q, Liu J, Evans DG, Duan X (2005) Synthesis and characterization of $\mathrm{Ni}_{1-\mathrm{x}} \mathrm{Zn}_{\mathrm{X}} \mathrm{Fe}_{2} \mathrm{O}_{4}$ spinel ferrites from tailored layered double hydroxide precursors. Mater Res Bull 40:1244-1255

14. Black C, Spence RR, Whiston K, Sproules S, Jackson SD (2018) Effect of excess iron on oxidative dehydrogenation of 1-butene over a series of zinc ferrite catalysts. Progr Petrochem Sci https:// doi.org/10.31031/PPS.2018.02.000534.

15. Monazam ER, Breault RW, Siriwardane R (2014) Kinetics of magnetite $\left(\mathrm{Fe}_{3} \mathrm{O}_{4}\right)$ oxidation to hematite $\left(\mathrm{Fe}_{2} \mathrm{O}_{3}\right)$ in air for chemical looping combustion. Ind Eng Chem Res 53:13320-13328

16. Ballarini N, Cavani F, Passeri S, Pesaresi L, Lee AF, Wilson K (2009) Phenol methylation over nanoparticulate $\mathrm{CoFe}_{2} \mathrm{O}_{4}$ inverse spinel catalysts: the effect of morphology on catalytic performance. Appl Catal A 366:184-192

17. Sepelak V, Indris S, Heitjans P, Becker KD (2007) Direct determination of the cation disorder in nanoscale spinels by NMR, XPS, and Mössbauer spectroscopy. J Alloys Compd 434-435:776-778

18. Zhang Z, Wang Y, Tan Q, Zhong Z, Su F (2013) Facile solvothermal synthesis of mesoporous manganese ferrite $\left(\mathrm{MnFe}_{2} \mathrm{O}_{4}\right)$ microspheres as anode materials for lithium ion batteries. J Colloid Interface Sci 398:185-192

19. Mittal VK, Bera S, Nithya R, Srinivasan MP, Velmurugan S, Narasimhan SV (2004) Solid state synthesis of Mg-Ni ferrite and characterization by XRD and XPS. J Nucl Mater 335:302-310

20. Du J, Liu Z, Wu W, Li Z, Han B, Huang Y (2005) Preparation of single-crystal copper ferrite nanorods and nanodisks. Mater Res Bull 40:928-935

21. Hong D, Yamada Y, Nagatomi T, Takai Y, Fukuzumi S (2012) Catalysis of nickel ferrite for photocatalytic water oxidation using $\left[\mathrm{Ru}(\mathrm{bpy})_{3}\right]^{2+}$ and $\mathrm{S}_{2} \mathrm{O}_{8}{ }^{2-}$. J Am Chem Soc 134:19572-19575

22. Karpova SS, Moshnikov VA, Maksimov AI, Mjakin SV, Kazantseva NE (2013) Study of the effect of the acid-base surface properties of $\mathrm{ZnO}, \mathrm{Fe}_{2} \mathrm{O}_{3}$ and $\mathrm{ZnFe}_{2} \mathrm{O}_{4}$ oxides on their gas sensitivity to ethanol vapor. Semiconductors 47:1026-1030

23. Kester E, Gillot B (1998) Cation distribution, thermodynamic and kinetics considerations in nanoscaled copper ferrite spinels. New experimental approach by XPS and new results both in the bulk and on the grain boundary. J Phys Chem Solids 59:1259-1269

24. Chinnasamy C, Narayanasamy A, Ponpandian N, Chattopadhyay $\mathrm{K}$, Guerault H, Greneche J (2001) Ferrimagnetic ordering in nanostructured zinc ferrite. Scripta Mater 44:1407-1410

25. Ichiyanagi Y, Kubota M, Moritake S, Kanazawa Y, Yamada T, Uehashi T (2007) Magnetic properties of Mg-ferrite nanoparticles. J Magn Magn Mater 310:2378-2380 
26. Cao J-G, Li J-J, Duan H-F, Lin Y-J (2012) Synthesis and characterisation of manganese-copper spinel ferrite powders. Chem Res Chin Universities 28:590-593

27. Hofman M, Campbell SJ, Ehrhardt H, Feyerherm R (2004) The magnetic behaviour of nanostructured zinc ferrite. J Mater Sci 39:5057-5065

28. Eyubova SM, Amirbekov EN, Aliev FV, Yagodovskii VD (2003) Catalytic transformation of butene- 1 and butene-2 on ferritecontaining catalysts with spinel structures. Russ J Phys Chem A 77:1069-1073

29. Ma J, Liu C, Chen K (2020) Insight in the relationship between magnetism of stoichiometric spinel ferrites and their catalytic activity. Catal Commun 140:105986

30. Christoskova STG, Danova N, Georgieva M, Argirov OK, Mehandzhiev D (1995) Investigation of a nickel oxide system for heterogeneous oxidation of organic compounds. Appl Catal A 128:219-229

31. Park J-H, Row K, Shin C-H (2013) Oxidative dehydrogenation of 1-butene to 1,3-butadiene over $\mathrm{BiFe}_{0.65} \mathrm{Ni}_{\mathrm{x}} \mathrm{Mo}$ oxide catalysts: effect of nickel content. Catal Commun 31:76-80

32. Carley AF, Jackson SD, O'Shea JN, Roberts MW (1999) The formation and characterisation of $\mathrm{Ni}^{3+}$ - an X-ray photoelectron spectroscopic investigation of potassium-doped Ni(110)-O. Surf Sci 440:L868-L874

33. Kiyokawa T, Ikenaga N (2017) Oxidative dehydrogenation of but-1-ene with lattice oxygen in ferrite catalysts. Appl Catal A 536:97-103

34. Tanabe K, Misono M, Ono Y, Hottori H (1989) New solid acids and bases: their catalytic properties. Elsevier, Amsterdam

35. Finocchio E, Busca G, Lorenzelli V, Trombetta M, Rossini SA (1996) IR study of alkene allylic activation on magnesium ferrite and alumina catalysts. J Chem Soc Faraday Trans 92:4687-4693

36. Putnis A (1992) An introduction to mineral sciences. Cambridge University Press, New York

37. Anantharaman MR, Jagatheesan S, Malini KA, Sindhu A, Narayanasamy A (1998) On the magnetic properties of ultra-fine zinc ferrites. J Magn Magn Mater 189:83-88

38. Hochepied JF, Bonville P, Pileni MP (2000) (2000) Nonstoichiometric zinc ferrite nanocrystals: syntheses and unusual magnetic properties. J Phys Chem 104:905-912

Publisher's Note Springer Nature remains neutral with regard to jurisdictional claims in published maps and institutional affiliations. 